\title{
Atypical presentation of Lynch Syndrome: a case report
}

\author{
Shanna Gustafson ${ }^{*}$, Whitney Ducaine ${ }^{\dagger}$, Dana Zakalik \\ From 14th Annual Meeting of the Collaborative Group of the Americas on Inherited Colorectal Cancer \\ Dallas, TX, USA. 12-13 October 2010
}

\section{Background}

Hereditary Breast and Ovarian Cancer (HBOC) syndrome due to mutations in BRCA1 and BRCA2 is associated with an increase in risk for primarily breast cancer and ovarian cancer. Lynch syndrome (LS), due to mutations in MLH1, MSH2, MSH6, and PMS2 is typically associated with an increase in risk for chiefly colorectal cancer and endometrial cancer. Ovarian cancer risk is also increased in LS, however less so than in HBOC.

\section{Method}

We describe a rare presentation of LS, diagnosed in a patient who presented at the age of 41 with a suspected primary ovarian cancer. Her family history was significant for a sister with breast cancer at the age of 29 found to carry a BRCA1 variant of uncertain significance; a mother who passed away from ovarian cancer; and a father with prostate cancer, and a paternal family history significant for breast cancer, pancreatic cancer, and a possible ovarian cancer. No colorectal or endometrial carcinoma was reported in maternal or paternal family history.

\section{Result}

Calculated BRCAPRO likelihood of a BRCA1/2 mutation, with a primary ovarian carcinoma as the probands diagnosis, was $90.2 \%$ [1]. Full clinical testing for mutations in BRCA1 and BRCA2 was pursued and was negative for any deleterious mutations or variants of uncertain significance in this patient.

Pathologic analysis of the patient's resected ovarian mass reported suspicion of GI or hepatobiliary origin due to positive staining for CK7, CEA and CK20. Due

\footnotetext{
* Correspondence: Shanna.gustafson@beaumonthospitals.com

† Contributed equally

Cancer Genetics Program, Beaumont Hospital, Royal Oak, MI, 48073, USA
}

to the history of multiple ovarian tumors in the family; the possibility of a primary GI tumor at a young age in the probands; and the negative $\mathrm{HBOC}$ testing; LS genetic testing was pursued and detected a deleterious MSH 2 mutation, IVS5+3A $>$ T. Appropriate testing and surveillance for Lynch Syndrome associated cancers for the patient and at risk relatives can now be pursued.

\section{Conclusion}

This case emphasizes the importance of consideration of Lynch syndrome as well as HBOC in all families presenting with multiple ovarian cancers and the crucial element which pathology plays in accurate risk assessment.

Published: 10 March 2011

Reference

1. Berry DA, Iverson ES Jr, et al: BRCAPRO validation, sensitivity of genetic testing of BRCA1/BRCA2, and prevalence of other breast cancer susceptibility genes. J Clin Oncol 2002, 20(11):2701-12.

doi:10.1186/1897-4287-9-S1-P10

Cite this article as: Gustafson et al:: Atypical presentation of Lynch Syndrome: a case report. Hereditary Cancer in Clinical Practice 2011 9(Suppl 1):P10.

Submit your next manuscript to BioMed Central and take full advantage of:

- Convenient online submission

- Thorough peer review

- No space constraints or color figure charges

- Immediate publication on acceptance

- Inclusion in PubMed, CAS, Scopus and Google Scholar

- Research which is freely available for redistribution

Submit your manuscript at www.biomedcentral.com/submit
C Biomed Central

\section{Biomed Central}

